\title{
LIVROS DIDÁTICOS DE FÍSICA E SUA (SUB)UTILIZAC̣̃̃O NO ENSINO MÉDIO
}

\author{
Luciana Bagolin Zambon* \\ Eduardo Adolfo Terrazzan**
}

RESUMO: Apresentamos uma síntese dos resultados de uma investigação sobre a utilização de Livros Didáticos (LD) de Física em Escolas Públicas de Educação Básica (EPEB). Para a coleta de informações, utilizamos questionários e realizamos entrevistas com professores de Física de EPEB na cidade de Santa Maria/RS. Podemos afirmar que os professores não costumam ficar presos aos LD, mas parecem ficar presos a uma certa "forma de ensinar Física" que se constitui em parte pela tradição já naturalizada de como ensinar Física e em parte pela sua própria experiência profissional docente. Essa forma de ensinar tem os exercícios como ponto central, e a presença de LD no cotidiano escolar, reafirmada de modo mais intenso a partir do PNLD, não tem contribuído para modificá-la.

Palavras-chave: Utilização de livros didáticos. Ensino de Física. PNLD.

\section{LIBROS DIDÁCTICOS DE LA FÍSICA Y SU (SUB)UTILIZACIÓN EN LA SECUNDARIA}

RESUMEN: Presentamos una síntesis de los resultados de una investigación de Libros Didácticos (LD) de Física en Escuelas Públicas de Educación Básica (EPEB). Para la recolección de informaciones, utilizamos cuestionarios y realizamos entrevistas con maestros de la Física de EPEB en la ciudad de Santa Maria/RS. Podemos afirmar que los maestros no suelen quedarse presos a los LD, pero parecen estar presos a una cierta "manera de enseñar a la Física", que se constituye en parte por la tradición ya naturalizada de cómo enseñar la Física y en parte por su propia experiencia profesional docente. Esa forma de enseñar tiene como punto central los ejercicios, y la presencia de LD en el cotidiano escolar, reafirmada de modo más intenso a partir del PNLD, no han contribuido para modificarla.

Palabras clave: Utilización de libros didácticos. Enseñanza de la Física. PNLD.

\section{PHYSICS TEXTBOOKS AND ITS UNDER-UTILIZATION IN HIGH SCHOOL}

ABSTRACT: We present a summary of the results of an investigation about the use of Physics textbooks (LD) in basic education public schools (EPEB). To collect information, we used questionnaires and interviews with EPEB Physics teachers in Santa Maria/RS. We can say that teachers do not get stuck to the LD, but seem to get stuck at a "way of teaching physics" that is constituted partly by the tradition

\footnotetext{
*Doutora em Educação pela Universidade Federal de Santa Maria (UFSM), Santa Maria - RS, Brasil. Professora do Departamento de Administração Escolar da UFSM. Líder do Grupo de Pesquisa "Políticas Educacionais, Escola e Trabalho Docente." Email: <luzambon@gmail.com>.

* *Doutor em Educação pela Universidade de São Paulo (USP), São Paulo - SP, Brasil. Professor do Departamento de Metodologia do Ensino da UFSM, Líder do Grupo de Estudos, Pesquisas e Intervenções INOVAEDUC "Inovação Educacional, Práticas Educativas e Formação de Professores" Email: <eduterranec@ymail.com>.
} 
already traditional on how to teach Physics and partly by their own teaching experience. This way of teaching has exercises as the central teaching point and the LD's presence in daily school, reaffirmed more intensely from PNLD, has not contributed to change it.

Keywords: Use of textbooks. Physics teaching. PNLD. 


\title{
INTRODUÇÃO
}

Este artigo se insere nas discussões acerca dos programas de material didático do governo federal, em particular, do Programa Nacional do Livro Didático (PNLD). Esses programas têm a intenção de contribuir para a garantia de materiais didáticos de qualidade, disponíveis para subsidiar o desenvolvimento dos processos de ensino e de aprendizagem em Escolas Públicas de Educação Básica (EPEB), e são desenvolvidos com o intuito de dar conta de um dos aspectos que, desde a Constituição de 1988 (artigo 208), constitui dever do Estado com a educação, a saber: "VII - atendimento ao educando no ensino fundamental, através de programas suplementares de material didático-escolar, transporte, alimentação e assistência à saúde".

Assim, considerando-se a amplitude que esses programas de material didático assumiram na atualidade no Brasil (tornando nosso país o maior comprador de livros didáticos) e considerando ainda a presença dos Livros Didáticos (LD) reafirmada, a partir do PNLD, no cotidiano das escolas e das salas de aula, de uma forma mais intensa e com uma perspectiva de utilização de melhor qualidade, entendemos que seja de extrema importância, no contexto atual, compreender de que modo esse programa tem incidido nas Escolas de Educação Básica, como os livros têm sido escolhidos, utilizados e, em especial, como os planejamentos didático-pedagógicos dos professores se relacionam com os livros escolhidos por eles.

Em particular, quando se trata da utilização de LD na educação básica, é comum assumir-se o pressuposto de que o livro tem exercido papel central no ensino. Pesquisas realizadas nas décadas de 1970 e 1980, por exemplo, apontavam o LD como elemento principal das aulas e como material privilegiado para utilização pelo professor.

Pretto (1985), ao investigar livros didáticos de Ciências, afirma que os professores têm tornado o livro o carro chefe de seu trabalho, o que seria decorrência do fato de que os professores não possuem condições aceitáveis de trabalho, salário e formação adequada para a realização de um bom trabalho em sala de aula.

Em revisão de literatura sobre as pesquisas relativas ao livro, Freitag et al. conclui, em relação à utilização desse material, que "o livro não é visto como um instrumento de trabalho auxiliar na sala de aula, mas sim como a autoridade, a última instância, o critério absoluto de verdade, o padrão de excelência a ser adotado na aula" (FREITAG et al., 1987, p. 93).

Molina afirma, na introdução de seu texto, que

\begin{abstract}
Mesmo se considerarmos o peso expressivo representado pelas aulas expositivas nas escolas de todos os níveis, em geral seu fecho é sempre o mesmo: "Agora, leiam o capítulo tal." "Estudem tal ponto." (...) Pode-se mesmo afirmar que, muitas vezes, o livro didático é um elemento tão presente na sala de aula quanto o próprio professor. (MOLINA, 1988, p. 13).
\end{abstract}

Esses estudos convergem para uma mesma constatação: a utilização frequente e exclusiva do LD e a forte presença desse material no ensino. Temos, porém, de considerar o contexto educacional no qual esses estudos foram produzidos. Com o processo de democratização de acesso à escola, ainda na década 
de 1960, começa a mudar o perfil econômico e cultural dos alunos e também o do professor. A ampliação do número de vagas nas escolas foi acompanhada do aumento do número de professores, muitos deles com formação precária e com poucas possibilidades de formação continuada adequada. Assim, esses professores, em geral, passaram a depender, cada vez mais, dos livros escolares (ROJO, 2005).

É nesse contexto, portanto, que as pesquisas acima referidas apontavam para uma utilização exclusiva desses livros no ensino. Analisar esse contexto e levar em conta as considerações feitas pelos autores citados não significa uma denúncia à utilização, propriamente dita, do livro pelo professor. Assim, concordamos que "se um professor usa um livro didático, isso não significa necessariamente que ele seja malformado, ignorante, como fazem supor as metáforas de 'muleta', 'escora' etc.” (MUNAKATA, 2002, p. 92). O problema reside, em nosso ponto de vista, na utilização exclusiva do livro como material para consulta e como fonte única para preparação das aulas, o que certamente reduz a autonomia do professor em relação às decisões sobre a definição dos conteúdos de ensino e sobre as formas de abordagem desses conteúdos.

Não é possível, no entanto, assumir que essa ainda seja a realidade em escolas de educação básica no país. De fato, consideramos que pouco sabemos sobre as formas como os livros didáticos vêm sendo utilizados, em um contexto em que todos os alunos da educação básica recebem livros, escolhidos pelos professores, mediante um mecanismo próprio, diferentemente do que acontecia na década de 1980.

Assim, trabalhos mais recentes apontam para uma utilização mais ampla do LD. Megid Neto e Fracalanza (2003), por exemplo, apontam os resultados de uma investigação realizada com professores de ciências, que evidencia a utilização do livro como uma das fontes para a preparação das aulas, como apoio ou fonte bibliográfica, o que sugere que o livro não é seguido do início ao fim. Esses resultados também estão presentes na investigação de Santos (2007), que constatou, para os sujeitos investigados, que o livro não se constitui como principal e único elemento de seu trabalho em sala de aula.

Por outro lado, Santos (2009) afirma que as adaptações realizadas por professores para utilização dos livros em aulas de português não figuram ajustes significativos. Timbo (2009) e Miranda (2009) apontam para a utilização de apenas parte do LD, ou seja, do texto principal e de exercícios. Espíndola (2003) constata, em seu estudo, que há, entre os professores investigados, uma dualidade entre autonomia/sujeição na relação entre os professores e o livro adotado.

Portanto, essas investigações indicam uma variedade de usos dos livros didáticos, sendo impossível apontar para um consenso quando se trata da utilização desse material. Assim, reconhecemos a necessidade de realização de estudos mais sistemáticos sobre a utilização de livros na educação básica.

Em trabalho de revisão de literatura sobre o tema "Livro Didático", especificamente na área de educação em ciências (ZAMBON, 2012), realizado em teses/dissertações e em artigos publicados em periódicos acadêmicocientíficos, constatamos que são raras as pesquisas nessa área e, em especial, na área de ensino de Física, que problematizam aspectos relacionados à utilização do LD por professores e alunos em sala de aula ou que abordam os processos de seleção de livros didáticos realizados por professores. Neste trabalho de revisão, 
identificamos 127 teses/dissertações da área de pesquisa em educação em ciências sobre a temática "Livro Didático", disponibilizadas no banco de dados do Centro de Documentação em Ensino de Ciências (CEDOC/UNICAMP - período 1996 a 2008) e no Banco de Teses da CAPES (período de 2007 a 2010) e 46 artigos publicados em nove Periódicos Acadêmico-Científicos ${ }^{1}$ também dessa área (entre 2007 e 2011). Mais recentemente, a partir de um trabalho de atualização desse levantamento nos nove periódicos da área de Educação em Ciências, no período 2012-2016, identificamos 42 artigos publicados sobre a temática "Livro Didático".

Constatamos que a grande maioria das teses/dissertações e dos artigos identificados em nosso levantamento refere-se à análise textual de livros didáticos (investigando, por exemplo, concepções de natureza veiculadas por livros didáticos, formas de abordagem de algum conteúdo conceitual etc.) e à utilização de recursos e estratégias didáticas em livros didáticos. No entanto, as investigações que se ocupam das formas de utilização de livros didáticos em sala de aula e dos processos de escolha dos livros didáticos porprofessores de Escolas Públicas de Educação Básica (EPEB) são muito raras. Tal resultado se mantém na análise dos artigos publicados nos últimos cinco anos, nos quais não foi encontrada nenhuma pesquisa sobre a utilização de Livros Didáticos por professores.

Dentre as pesquisas que investigam essa temática, encontramos a dissertação de Santos (2001), que analisa a utilização do LD em aulas de Física no Ensino Médio. Segundo essa pesquisadora, ficou evidenciado um forte papel mediador do livro nas aulas investigadas, na medida em que os textos e os exercícios presentes no LD foram reproduzidos pelo professor, reforçando concepções de ensino e de aprendizagem pautadas na transmissão e na recepção/memorização de informações.

A outra pesquisa (BAGANHA, 2010) investigou como professores de Ciências utilizam o LD. A pesquisadora verificou, em sua dissertação, que as professoras utilizam o livro como organizador do currículo escolar, pois selecionam os conteúdos presentes nesses materiais, adequando-os à realidade de onde trabalham e às concepções pedagógicas que possuem. Constatou, também, que o LD não é utilizado como única fonte de informação, mas como material de apoio, fonte de informação e pesquisa, tanto para o aluno quanto para o professor.

A lacuna de pesquisas sobre essa temática aponta para a emergência da realização de investigações que se ocupem da utilização de livros didáticos por professores de Física. Para isso, realizamos investigação (ZAMBON, 2012) que procurou responder, dentre outros aspectos, às seguintes questões de pesquisa: (1) Como professores de Física de EPEB utilizam livros didáticos na organização e no desenvolvimento de suas aulas? (2) De que modo a formação acadêmica e a experiência profissional de professores de Física de EPEB influenciam na utilização de livros didáticos? (3) De que forma os Livros Didáticos de Física, selecionados em cada EPEB, articulam-se com a organização e o desenvolvimento das programações curriculares dessas escolas e das estruturações curriculares da disciplina de Física?

\section{PROCEDIMENTOS METODOLÓGICOS UTILIZADOS PARA DESENVOLVIMENTO DO ESTUDO}

Para responder a nossas questões de pesquisa, utilizamos, como fontes de informação professores de Física em serviço em EPEB da cidade de Santa Maria/ 
RS, e questionários e entrevistas estruturadas mediante roteiro como instrumentos para coleta de informações.

O universo da pesquisa envolveu, inicialmente, todas as 27 Escolas Públicas de Educação Básica da cidade de Santa Maria/RS que possuem o Ensino Médio como etapa de escolaridade, das quais 24 são da rede pública estadual e três da rede pública federal.

No início do ano letivo de 2011, contatamos as equipes gestoras de todas as 27 escolas, com o intuito de coletar informações cadastrais sobre os professores de Física, informar os objetivos de nossa investigação e questionar sobre a possibilidade de realização da pesquisa com esses professores. Constatamos que havia, na época, um total de 58 professores de Física em serviço nessas 27 escolas. Em seis delas, recebemos, da coordenação pedagógica, resposta negativa para a realização de nossa pesquisa, o que excluiu a possibilidade de conversarmos com os professores de Física dessas escolas.

Depois desse contato com a coordenação pedagógica, iniciamos o contato direto com os professores de Física das 21 escolas que responderam positivamente à nossa solicitação. Nesse contato direto com os professores de Física, explicamos os objetivos de nossa pesquisa e distribuímos os questionários para eles. Tivemos dificuldades para contatar diretamente alguns professores, muitas vezes porque eles não se encontravam na escola no momento de nossa visita e, em outros casos, porque os professores estavam em sala de aula. Nesses casos, os questionários foram entregues à coordenação pedagógica, que ficou responsável pela sua distribuição aos professores de Física.

O questionário constava de duas partes - a primeira solicitava um conjunto de informações cadastrais, relativas à formação acadêmica e experiência profissional dos professores; a segunda apresentava um conjunto de oito questões, abertas e fechadas, relativas aos materiais didáticos utilizados para a preparação das aulas e sua forma de utilização, às formas pelas quais aconteceram os processos de escolha de livros didáticos de Física no âmbito do PNLEM/2007, às formas de utilização de livros didáticos de Física pelo professor e por alunos, à avaliação da qualidade dos livros distribuídos no âmbito do PNLEM/2007, às formas de utilização de outros materiais didáticos por alunos.

Obtivemos retorno de 27 professores, atuantes em 18 escolas, que entregaram o questionário e que, portanto, constituem a amostra dessa pesquisa. Todos os questionários recebidos foram transcritos, e as respostas armazenadas em acervo físico e digital.

Depois de realizadas análises parciais das informações coletadas mediante os questionários, realizamos entrevistas com professores de Física. Para tanto, foi feito novo contato com os professores, durante os meses de novembro e dezembro de 2011, buscando aprofundar as informações coletadas. Devido à proximidade com o calendário de provas e a realização de uma greve de professores nas escolas da rede estadual do Rio Grande do Sul, a partir da segunda quinzena de novembro, muitos professores não puderam participar das entrevistas. No total, foram entrevistados nove professores de Física, sendo as entrevistas gravadas em áudio e transcritas.

O roteiro de entrevista era composto de quatro blocos que tratavam sobre a utilização do livro didático, a organização do processo de escolha de livros didáticos 
nas escolas no âmbito do PNLD Ensino Médio 2012, os critérios utilizados para essa escolha e a qualidade dos livros didáticos recomendados pelo PNLD.

Para proceder ao tratamento e análise das informações, utilizamos a técnica da categorização temática ou codificação (GIBBS, 2009), a qual está ancorada na perspectiva da Teoria Fundamentada (CHARMAZ, 2009). A teoria fundamentada é baseada no uso de categorias geradas a partir das informações coletadas, sem desconsiderar, é claro, que nossos aportes conceituais são levados para a coleta e para a análise das informações.

A análise baseada na categorização temática inicia-se por uma codificação mais descritiva e próxima dos termos utilizados pelos informantes e passa, em seguida, à categorização analítica, na qual se procuram formas novas, mais teóricas, para a compreensão das informações coletadas (GIBBS, 2009). Assim, nossas categorias de análise resultaram de um processo que se iniciou pela leitura cuidadosa das informações coletadas em cada entrevista e questionário, buscando os aspectos que nos pareciam mais significativos ou mais frequentes para desenvolver categorias provisórias. Tais categorias foram comparadas sucessivamente aos dados, para testá-las, modificá-las e reelaborá-las como nossas categorias de análise.

\section{CONSTITUIC̣ÃO E DISCUSSÃO DE RESULTADOS}

É importante notar que a soma das frequências associadas às categorias muitas vezes não corresponde ao número de professores que responderam os questionários (27) ou ao de professores entrevistados (9), seja porque, em alguns critérios de análise, as categorias utilizadas não são excludentes, seja porque alguns professores atuam em mais de uma escola e possuem práticas diferentes em cada uma delas.

Procuramos entender, inicialmente, como os professores se instrumentalizam a partir do LD no processo de organização das aulas. Nas respostas dadas ao questionário por 12 professores, encontramos referência à utilização dos livros como fonte para organização de listagens de exercício. E em outras nove respostas, encontramos referência à utilização do LD como fonte básica para subsidiar o tratamento dos conteúdos conceituais da área disciplinar de Física; os professores, nesse caso, dizem que retiram do livro textos para subsidiar sua exposição em sala de aula.

Um único professor disse utilizar o livro como fonte para seleção de experimentos didático-científicos para subsidiar o desenvolvimento de atividades didáticas baseadas nesse recurso. Quatro professores utilizam o livro como fonte para a realização de pesquisas, de onde subentende-se que o professor consulta o livro para organizar o planejamento e/ou solicita que os alunos utilizem o livro como base para atividades didáticas de pesquisa. Outro professor menciona que utiliza o livro como fonte de consulta para seus estudos pessoais, sem mais detalhamentos. Além disso, os professores informaram que também costumam utilizar Sistemas Apostilados de Ensino², revistas, semanais ou mensais, jornais diários e materiais obtidos pela internet para a preparação das aulas.

Já pelas respostas obtidas mediante a realização das entrevistas, tratando especificamente da utilização de livros Didáticos no processo de organização das aulas, encontramos três categorias, estabelecidas a posteriori, conforme o quadro abaixo. 
Quadro 1 - Categorias de análise definidas para 0 critério “Papel do Livro Didático na organização das aulas"

\begin{tabular}{|c|l|}
\hline $\mathbf{N}^{\circ}$ & \multicolumn{1}{|c|}{ CATEGORIAS } \\
\hline 1 & $\begin{array}{l}\text { Enriquecer a intervenção didática. Nesses casos, o professor busca elementos no LD } \\
\text { para enriquecer uma intervenção didática já previamente organizada }\end{array}$ \\
\hline 2 & $\begin{array}{l}\text { Organizar listas de exercícios. Utiliza o livro apenas como fonte para organização de } \\
\text { listagens de exercícios }\end{array}$ \\
\hline 3 & $\begin{array}{l}\text { Organizar a utilização do livro didático em sala de aula. O professor integra o LD à sua } \\
\text { intervenção didática }\end{array}$ \\
\hline
\end{tabular}

Cinco professores de Física afirmaram que utilizam os livros para enriquecer sua intervenção didática, previamente organizada. Em alguns casos, a análise do livro é feita para evitar que haja conflitos entre sua intervenção e aquela proposta no livro, o que se reduz, às vezes, a verificar se a terminologia utilizada é a mesma. A frase abaixo é representativa dessa categoria:

Antes [das aulas] eu consulto o livro, [para analisar] se aquela parte abordada no livro está de acordo com aquilo que eu me comprometo em desenvolver. Se eu não gosto daquela abordagem, eu vou para outro material (...). PF 02

Semelhante às respostas dadas ao questionário, percebemos novamente uma grande presença dos exercícios, uma vez que cinco professores afirmaram utilizar livros como fonte para a organização de listas de exercícios. Além disso, professores também afirmam que o LD adotado não dá conta de abranger os exercícios que querem utilizar; por isso, outros livros são consultados, e às vezes ocorre consulta na internet, para preparar listagens com exercícios extras, além daqueles existentes no livro adotado.

A preparação das aulas sempre eu pego mais de um livro didático, e pego os exercícios, principalmente aqueles de vestibular, os mais complicados, para eles terem noção de como vão ser as provas. Ou mesmo exercícios de concurso, eu tento preparar os mais difíceis. Então é isso, sempre pegando os livros didáticos que ajudam bastante a gente preparar as aulas. PF 11

Com apenas uma ocorrência, identificamos, na categoria 3, o caso de um professor que integra o LD à sua intervenção didática:

(...) geralmente eu faço os exercícios antes, dou uma olhada nos exemplos, logicamente leio o texto, até para que depois [na aula] eu possa ir pedindo para eles, destacando aquilo que é mais importante. E às vezes eu faço assim, eu dou um roteiro, então eu leio o capítulo, eu vejo como o capitulo está estruturado, como é que são os exemplos, (...) eu faço um exercício complementar, eu olho como ele está estruturado, será que este exemplo the permite fazer quantos destes exercícios? (...) PF 18-03

Esse professor prepara as aulas selecionando partes do livro para utilização 
direta com os alunos, preparando roteiros para a leitura do livro pelos alunos e analisando os exemplos para avaliar se auxiliam na resolução de exercícios.

Encontramos ainda dois professores que dizem não utilizar livros no processo de organização das aulas. Um deles parece preferir utilizar outros materiais, citando a consulta à internet, ao portal do professor do MEC e à seleção de exercícios de exames vestibulares. Para outro professor, sua experiência docente é suficiente para embasar suas exposições e intervenções didáticas, por isso a consulta aos livros é desnecessária.

O fato de os professores possuírem uma intervenção didática pronta, em geral construída pela sua experiência, ao longo dos anos de atuação profissional em sala de aula, e de utilizar o livro apenas como uma consulta para enriquecer sua intervenção ou evitar conflitos é confirmada em algumas falas, quando falam sobre a importância dos livros. Esses professores afirmam que a maior importância do livro está na possibilidade de o aluno ter para si um material didático que dificilmente teria, caso precisasse adquiri-lo com recursos próprios; porém, no processo de organização das aulas, o LD não exerce um papel muito relevante, seja porque o professor já tem experiência suficiente para organizar sua intervenção, seja porque utiliza outros materiais para preparar suas aulas (em geral, para preparar novas listagens de exercícios).

As respostas a seguir foram dadas à questão sobre a importância dos livros no processo de organização das aulas e em sala de aula:

Eu acho que a importância maior é em sala de aula, sabe, porque agiliza o processo, não é para preparar a aula, no meu caso. No meu caso que tenho 22 anos de Física, o lado bom do livro nesse ponto é esse, agiliza o trabalho em sala de aula, porque o aluno já está ali com o conteúdo. PF 01

Para preparar a aula eu não vejo assim grande coisa no sentido, a não ser tu dar uma lida. Quando o livro é novo a gente lê, depois tu já conhece, (...) mas para eles eu acho importante, ter o material, porque só aquilo que está no caderno, com dois períodos de aula, que agora nós temos só dois períodos de Física, tu não faz nada, tu faz de conta que ensinou alguma coisa. PF 18-02

Em relação à Utilização de Livros Didáticos em sala de aula, identificamos, nas respostas dadas aos questionários, um conjunto de professores (10), o qual representa a maior parte das respostas, que utilizam o LD para subsidiar as atividades de leitura dos alunos, em sala de aula, sobre os conteúdos da área disciplinar de Física e/ou como fonte para seleção de exercícios a ser resolvidos pelos alunos. Agrupamos, nessa categoria, as respostas em que os termos leitura, textos, conteúdos foram utilizados e que estamos subentendendo como sendo utilização do livro para subsidiar o tratamento dos conteúdos. Desse conjunto de respostas, dois professores dizem utilizar o Livro Didático apenas como fonte para a seleção de exercícios a ser resolvidos pelos alunos, e outros dois professores apenas como subsídio para o tratamento dos conteúdos. Essas quatro respostas podem ser compreendidas como uma variação da primeira categoria, com a diferença de que os professores utilizam o livro para uma única finalidade (ou para resolução de 
exercícios ou para tratamento dos conteúdos, mediante leitura e estudo).

Um professor disse que utiliza o livro como apoio, de onde subentendemos que o livro não é adotado integralmente ou trabalhado como único material nas aulas. Outro disse que realiza um estudo dirigido em sala de aula, o que parece indicar que o livro é utilizado seguindo-se um procedimento no qual ele orienta ou dirige a leitura/estudo dos alunos. Por fim, dois professores dizem não utilizar os livros, e um justifica que não há livros suficientes para todos os alunos.

A partir das entrevistas realizadas, encontramos coerência com as constatações já apresentadas, mas com um maior detalhamento. A partir dessas entrevistas, definimos três categorias, conforme o quadro que se segue.

Quadro 2 - Categorias de análise definidas para 0 critério "Utilização do Livro Didático selecionado em sala de aula"

\begin{tabular}{|c|l|}
\hline $\mathbf{N}^{0}$ & \multicolumn{1}{c|}{ CATEGORIAS } \\
\hline 1 & Fonte para obtenção de listagens organizadas de exercícios para resolução pelos alunos \\
\hline 2 & $\begin{array}{l}\text { Parte integrante da intervenção didática do professor, mediante leitura no decorrer da } \\
\text { aula, paralelamente à explicação do professor ou solicitação de leitura preparatória } \\
\text { em casa para a aula }\end{array}$ \\
\hline 3 & Não é utilizado em sala de aula \\
\hline
\end{tabular}

Coerente com a análise anterior, constatamos que a grande maioria dos professores de Física entrevistados (7) utiliza o livro em sala de aula como uma fonte para obtenção de listagens já organizadas de exercícios para resolução pelos alunos. Nesses casos, o professor realiza uma intervenção didática praticamente independente do LD, que é utilizado apenas como fonte de exercícios, excluindo a necessidade de cópia de exercícios do quadro ou de utilização de cópias xérox de listas de exercícios.

Eu utilizo [o LD] diariamente; o aluno precisa trazer [o LD], (...). O livro não é lido em sala de aula. Eu simplesmente pego, por exemplo o capítulo 38, eu pego, abordo todo o conteúdo, não necessariamente na sequência que está ali, eu vou expondo, muitas vezes eu faço outra sequência, porque não concordo com a sequência que o livro traz, mas o conteúdo está ali. (...) não é lido, o livro, ele é utilizado mais para fazer os exercícios (...). PF01

Porém, em alguns casos, ainda há necessidade de cópia de exercícios do quadro, quando os alunos não levam o livro para a sala de aula. Por exemplo:

(...) minhas aulas são mais assim: de eu dar um exercício, explico, dou um exemplo e mando eles fazerem outros [exercícios], pegando do livro, ou copiando no quadro, ou em exercícios em folha mimeografada (...) [porque] eles estão com o livro em casa, (...), mas eles não trazem, porque dizem que é muito pesado, que têm uns quantos [livros], então é difícil. [Aí eu acabo] passando exercícios [no quadro] (...). PF 11 
Em alguns casos, esses professores solicitam leitura/estudo do livro em casa, antes de provas, por exemplo:

[minha aula] mais é expositiva mesmo, eu pouco sigo o livro, aquela coisa de ler o livro e fazer resuminho, isso eu não faço. (...) [Em sala de aula, utilizo] os exercícios, basicamente, os exercícios para eles fazerem, para eles fazerem os exercícios práticos. (...) Eu cobro muito na prova a leitura do conteúdo, para estudar para a prova, eu cobro a parte teórica. Eu cobro muito, pelo menos que eles leiam, não o livro em si, mas que eles leiam alguma coisa sobre o conteúdo. PF 18-02

Essas constatações remetem para a forma como, em geral, as aulas de Física acontecem: leitura dos alunos e/ou explicação do professor sobre um assunto/ conceito da estrutura conceitual da Física, seguida da resolução de exemplos pelo professor e da resolução de exercícios similares pelos alunos. A resposta de um dos professores resume bem esse percurso:

Leitura [do aluno] no livro e exercícios de reforço, os quais os alunos fazem como temas [tarefas de casa]; e os exercícios de aplicação são feitos em aula, como modelo. PF 17-01

A frase selecionada abaixo exemplifica a importância que os exercícios têm nas aulas de Física, sob o ponto de vista dos professores.

[Quando] fechou um assunto, aí vamos fazer a fixação e aí vai (sic) surgindo as dúvidas; não venham querer me dizer que não é aí, porque é. Aquela história de aula conceitual, eu não concordo, porque aí não vai (sic) surgir as dúvidas do aluno, se não for eu aplicar uma equação, não vai surgir as dúvidas (...). PF 01

Para esse professor, a aprendizagem da Física só ocorre mediante a utilização de equações em exercícios. Porém, do nosso ponto de vista, isso não garante o entendimento do fenômeno/assunto envolvido, pois o aluno pode estar apenas realizando operações matemáticas, sem a compreensão das situações físicas envolvidas. Visão semelhante foi expressa na fala de PF 11, referindo-se à resolução de exercícios pelos alunos: "só assim eles aprendem”.

Verificou-se que apenas um único professor desenvolve um trabalho diferente em sala de aula, contemplado na categoria 2. Nesse caso, a utilização do LD é parte integrante da intervenção didática do professor, mediante a realização de leituras no decorrer da aula, intercaladas com sua intervenção, sempre acompanhada de explicações, ou mediante a solicitação de leitura em casa, com uma finalidade específica preparatória para a aula, ou seja, o professor organiza um roteiro para os alunos realizarem a leitura em casa, e essa tarefa é retomada depois em sala de aula. Apesar dessa compreensão, como podemos perceber no trecho abaixo, a resolução de exercícios pelos alunos também consiste em mecanismo utilizado por esse professor, como seguimento de sua intervenção:

Eu uso o livro assim para os aspectos históricos, geralmente eu leio junto com os alunos, faço uma leitura com eles, quando não, eu peço para eles lerem em casa. Leio com eles, 
peço para eles destacarem as coisas mais importantes, ai feito essa leitura ai eu passo para a parte dos exemplos, digamos que mais de aplicação, faço alguns exemplos, depois dos exemplos então eu faço alguns exercícios. PF18-03

Essas constatações indicam que as listagens de exercícios regulam parte significativa das atividades dos professores de Física, seja no processo de organização das aulas, como vimos antes, seja na utilização do livro em sala de aula, o que indica que a resolução de exercícios nas aulas de Física é um mecanismo integrante da cultura escolar.

Outras duas professoras dizem que não utilizam o livro em sala de aula. Uma delas afirma que o livro selecionado é de qualidade muito ruim, por isso sua aula é baseada na exposição e no diálogo com os alunos. A outra diz que tem receio em adotar apenas um livro para utilização com os alunos, por isso ela prepara seu próprio material, baseada em diversos livros, e tem apoio da escola para fazer cópias desses materiais para os alunos.

Em relação ao Papel do Liuro Didático selecionado na definição da sequência de assuntos, as respostas obtidas com as entrevistas realizadas foram agrupadas em duas categorias, conforme o quadro abaixo.

Quadro 3 - Categorias de análise definidas para o critério "Papel do Livro Didático selecionado na definição da sequência de assuntos"

\begin{tabular}{|c|c|}
\hline No & CATEGORIAS \\
\hline 1 & $\begin{array}{l}\text { Subsidiar o desenvolvimento da sequência de assuntos já determinada pelo Programa } \\
\text { do processo seletivo seriado de ingresso à UFSM }\end{array}$ \\
\hline 2 & Subsidiar o desenvolvimento da sequência de assuntos já determinada pelo professor \\
\hline
\end{tabular}

Em ambas as categorias, o papel do Livro Didático é o de subsidiar o desenvolvimento dos conteúdos de ensino em uma sequência já estabelecida, seja pelo programa do vestibular seriado, seja pelo professor.

Quase todos os professores (8) afirmam que a sequência de assuntos é determinada pelo programa (listagem de conteúdos conceituais) do Programa de Ingresso ao Ensino Superior (PEIES) da Universidade Federal de Santa Maria (UFSM), e as partes do LD selecionado são organizadas na mesma sequência de assuntos do Programa. O PEIES consiste em uma forma alternativa de ingresso à UFSM, na qual as provas são realizadas em três etapas, cada uma no final de uma das três séries do Ensino Médio. Recentemente, o PEIES foi extinto, dando lugar ao chamado Processo Seletivo Seriado (PS1, PS2 e PS3 - referindo-se às três provas, no final de cada série), que mantém, em geral, as mesmas características do PEIES.

Minha sequência é conforme o PS [Processo Seletivo Seriado], no caso agora, e como era o PEIES. Eu sigo nessa sequência, $1^{\circ}$ ano, $2^{\circ}$ ano e $3^{\circ}$ ano. (...) Eu faço conforme a UFSM e o livro vem depois, eu adapto. PF 05 
Seguindo basicamente o cronograma do PEIES e do [vestibular] seriado agora (...) [e depois] eu adapto a sequência de acordo com a necessidade (...). PF 18-02

O professor PF 02, apesar de seguir a programação do PEIES, realiza algumas alterações na programação de cada série, como afirma no trecho abaixo selecionado, ao contrário dos demais professores que parecem seguir fielmente a sequência estabelecida por esse programa.

\footnotetext{
Não, o meu livro não tem peso na [definição da] sequência nenhuma (...) vou pulando os capítulos, [porque] nós seguimos o vestibular, (...) o seriado. Então assim, ele não te dá liberdade de trabalhar com conteúdo de $1^{\circ}$, lá no $2^{\circ}$ ou $3^{\circ}$. Então esses conteúdos que são específicos da série a gente tem que trabalhar. Agora, a ordem de como a gente vai trabalhar esse conteúdo se é inicio ou final, isso não importa. PF 02
}

Para ter uma melhor ideia sobre a dimensão da influência que exerce essa programação no Ensino Médio nas escolas da cidade, selecionamos o trecho do depoimento do professor PF 06. O livro selecionado em sua escola, no âmbito do PNLD 2012, apresenta os assuntos "hidrostática" e "hidrodinâmica" no volume 1, pois podem ser classificados no tópico conceitual da Mecânica, comumente presente no volume 1 das coleções de Física. Ocorre que, na programação do PEIES, esses assuntos estão apresentados para a segunda série do Ensino Médio. Assim, o professor que segue rigorosamente essa sequência - como é o caso de boa parte dos professores das escolas de Santa Maria, com algumas exceções encontra dificuldades, pois o volume 1 dos livros didáticos adotados está com os alunos do primeiro ano, e os assuntos hidrostática e hidrodinâmica (presentes nesse volume) “devem" ser trabalhados no segundo ano. A alternativa relatada por vários professores tem sido a cópia xérox dos capítulos necessários para a utilização com os alunos da segunda série. A nova solução encontrada agora por um professor é relatada abaixo:

\footnotetext{
Não, [o livro] não é considerado [na decisão sobre a sequência], tanto porque esse livro que a gente escolheu não tem hidrodinâmica, eu pedi para o representante da [nome da editora] e ele conseguiu com o autor que vai vim (sic) um encarte, um suplemento de bidrodinâmica dentro do livro. (...) Vem um encarte de hidrodinâmica dentro do livro para nós, né, porque o único lugar que exige hidrodinâmica é Santa Maria, por exemplo, a UFRGS não precisa. Então vai vir junto para toda Santa Maria e para o interior, essas cidadezinhas ai, vem um encarte de bidrodinâmica. (...) PF 18-01
}

Fica evidente que a programação do vestibular seriado da UFSM é um fator determinante na definição das programações curriculares dos professores de Física, que parecem ter perdido sua autonomia na definição dos conteúdos de ensino.

Assim, aparentemente, não interessa a esses professores que o livro seja dividido em partes trabalhadas separadamente; não interessa discutir com os alunos a própria estrutura conceitual da Física e a forma como está organizada; em vez disso, interessa trabalhar com uma sequência definida por outros profissionais fora do contexto escolar. Portanto, quando se trata da definição dos conteúdos de ensino, “a questão está na transmissão de um conteúdo, aparentemente inquestionável, 
para o aluno e não [em] qual conteúdo é adequado para determinados objetivos do ensino de ciências" (CASSAB, MARTINS, 2008, p. 10).

O que vemos, então, é a adoção da programação do vestibular seriado da UFSM, a ponto de ela influenciar todo o trabalho docente desenvolvido por esses professores, até mesmo a escolha e a utilização do LD.

Dentre os professores investigados, porém, há uma exceção: um professor que diz que organiza sua própria seleção de conteúdos e as partes do livro (ou de outros materiais) são utilizadas conforme essa sua sequência. Ele afirma que atua em três escolas, e em uma delas, há uma maior pressão em relação ao vestibular seriado, mas, nas outras duas, não há esse tipo de exigência, por isso não precisa ficar atrelado àquela programação.

Portanto, pelas informações coletadas com os professores investigados, podemos concluir que, para esse grupo, o LD não assume nenhum papel relevante na definição da sequência de assuntos em aulas de Física, papel desempenhado pelos exames de ingresso à universidade.

Em relação às Influências da formação acadêmica e da experiência profissional de professores de Física na utilização de Livros Didáticos, estabelecemos duas categorias, conforme o quadro abaixo.

Quadro 4 - Categorias de análise definidas para 0 critério "Influências da formação acadêmica e da experiência profissional de professores de Física na utilização de Livros Didáticos"

\begin{tabular}{|c|l|}
\hline $\mathbf{N}^{\mathbf{0}}$ & \multicolumn{1}{|c|}{ CATEGORIAS } \\
\hline 1 & $\begin{array}{l}\text { Tanto a formação acadêmica como a experiência docente de sala de aula do professor } \\
\text { influenciam }\end{array}$ \\
\hline 2 & Apenas a experiência docente de sala de aula influencia \\
\hline
\end{tabular}

Constatamos que a maior parte dos professores considera que apenas a experiência docente de sala de aula influencia na utilização de livros didáticos e, de um modo geral, no desenvolvimento de seu trabalho docente. Apenas dois professores afirmam que a formação acadêmica, articulada com a experiência, também influencia.

(...) na realidade, eu fui aprender realmente a trabalhar a Física do Ensino Médio quando eu comecei a trabalhar. Não sei agora como é que está o curso, quantos anos faz? 20 anos que eu fiz o curso lá fora [na UFSM]. Eu saí sabendo mais conteúdos para seguir no mestrado do que [para] trabalhar no Ensino Médio. Então, eu fui... no meu dia-a-dia de trabalho que eu fui aprendendo. PF 01

(...) a prática ajuda, porque dai tu já está calejada [experiente] como diz o outro, mas no começo era complicado e todos, eu acredito que todos, os meus colegas que saíram da Matemática e foram para a Física devem ter passado pela mesma dificuldade, porque nós saímos dali, extremamente despreparados. (...) hoje não, hoje tu já tira de letra tudo, entendeu. Ai assim, tu até acaba descartando um pouco o livro, porque tu absorveu durante todos esse anos e o livro fica muito mais para eles [alunos] do que para a gente (...). PF 18-02 
(...) essa parte de desenvolver o conceito de fazer questões de pensar (...) que ela leva tu a pensar um problema, tu analisar para depois tu conseguir fazê-lo. (...) Além da [minha] prática, a formação [acadêmica também influenciou]. Sempre a formação foi muito forte nesse sentido, são coisas juntas. PF 02

Não conseguimos identificar, nas respostas dos professores, de modo explícito, a forma como os conhecimentos adquiridos durante sua experiência docente ou sua formação acadêmica influenciam no desenvolvimento de seu trabalho. Em geral, esses professores referem-se a conhecimentos da estrutura conceitual da Física (domínio conceitual), à forma de trabalhar em sala de aula e às reações dos alunos, como conhecimentos/saberes adquiridos na experiência docente.

Podemos dizer que esses professores constituíram um saber experiencial que acaba se tornando "norma" para o desenvolvimento de seu trabalho docente. Como mostra o estudo de Cormier, Lessard et al (1980, apud Gauthier, 2006) a grande maioria dos professores afirma ter aprendido a ensinar pela própria experiência. Em nosso caso, apesar de termos reduzido a questão à utilização do $\mathrm{LD}$, muitos falaram sobre sua prática docente, de um modo geral, apresentando um discurso semelhante.

Assim, ao longo da experiência docente, os professores acumularam uma forma de desenvolver as aulas de Física, baseada basicamente em uma intervenção didática, seguida da resolução de exemplos (para fornecer um "modelo" de resolução) e de um número grande de exercícios, e a presença dos livros, reafirmada de forma mais intensa no cotidiano das aulas de Física desde o PNLEM 2007, não tem contribuído para modificar (no sentido de trazer melhorias para) as práticas docentes dos professores, que acabam subutilizando o livro, na medida em que ficam restritos ao texto principal e aos exercícios.

Quanto à análise sobre a articulação dos livros didáticos selecionados com as orientações contidas nos projetos polititio-pedagógicos das escolas, as informações coletadas mediante entrevista foram organizadas em três categorias, as quais foram discriminadas em subcategorias, conforme o quadro abaixo.

Quadro 5 - Categorias de análise definidas para 0 critério "Adequação do Livro Didático de Física selecionado a aspectos presentes no PPP da escola"

\begin{tabular}{|c|c|c|}
\hline $\mathbf{N}^{\mathbf{O}}$ & CATEGORIAS & SUBCATEGORIAS \\
\hline \multirow[b]{2}{*}{1} & \multirow{2}{*}{$\begin{array}{l}\text { Em relação aos objetivos/finalidades } \\
\text { da escola, o livro didático selecionado } \\
\text { está adequado }\end{array}$} & Preparação para cidadania \\
\hline & & $\begin{array}{l}\text { Preparação para concursos, em particular, } \\
\text { para o vestibular }\end{array}$ \\
\hline 2 & $\begin{array}{l}\text { Em relação à estrutura organizativa da } \\
\text { escola, o livro didático selecionado não } \\
\text { está adequado }\end{array}$ & Trabalho articulado entre disciplinas \\
\hline \multirow[t]{2}{*}{3} & \multirow{2}{*}{$\begin{array}{l}\text { Em relação à proposta curricular e/ou } \\
\text { metodológica da disciplina de Física } \\
\text { na escola, o livro didático selecionado } \\
\text { está adequado }\end{array}$} & $\begin{array}{l}\text { Ensino de Física de modo articulado com } \\
\text { situações do cotidiano dos alunos }\end{array}$ \\
\hline & & Sequência de assuntos dos planos de ensino \\
\hline
\end{tabular}


Pelas informações coletadas, constatamos que a maioria dos professores (6) considera o livro adequado aos objetivos/finalidades da escola; três deles consideram que essa finalidade seja a preparação para a cidadania, e outros três consideram que seja a preparação para concursos, em especial, para o vestibular. Outros dois professores consideram, em particular, a proposta curricular e a proposta metodológica da disciplina de Física na sua escola, indicando que o livro escolhido está adequado à proposta de ensinar Física mediante articulação com o cotidiano dos alunos (um professor) e à sequência de assuntos definidos nos planos de ensino (um professor). Apenas um professor considera que o livro não está adequado com a estrutura organizativa definida na sua escola, que consiste no trabalho por áreas curriculares. Para esse professor, o livro ajuda apenas em parte, quando oferece elementos para fazer contextualização com outras áreas, mas isso é limitado.

As três falas abaixo são representativas das categorias com maior ocorrência:

(....) como um todo do que está previsto lá, preparar o aluno para a vida, para todos aqueles itens que formam um bom cidadão, (...) eu acho que [o livro] atende. PF 01

Acho que a gente quase nem tem muito acesso a esses documentos, para te dizer a verdade, mas eu acredito que sim, porque uma vez que a escola está... a proposta da escola é preparar o aluno, etc. tem um "eito" [quantidade grande] de palavrório bonito em todas as vezes que é falado, eu acredito que seja [adequado]. O problema é o fazer a tua parte aqui dentro; está no papel lá, beleza, qualquer um vai achar maravilhoso. O problema é tu entrar aqui e tentar pôr em prática aquilo ali quando eles não querem, os pais não estão nem ai (...) PF 18-02

(...) a proposta pedagógica é tu... no caso pra nós do Ensino Médio, (...) o interesse é visando a Universidade, mesmo que tu não tenha como objetivo primordial, porque não são todos os que vão fazer, só que assim, os que vão tem a oportunidade de ter.... né. Então como a nossa escola era credenciada no PEIES, e tem muito aluno que esta fazendo o PS1, PS2 e PS3 que vai fazer, entende, então era dentro disso. PF 05

Aquelas respostas que remetem para a articulação do livro com a finalidade de "formação do cidadão" acabam se configurando como discursos vazios, na medida em que não há elementos que indiquem como aquele livro selecionado contribui para essa formação e por quais motivos os demais livros não o fazem.

Assim, parecem ser mais palpáveis/concretas (apesar da incoerência, de nosso ponto de vista, com as finalidades amplas do Ensino Médio) aquelas respostas que afirmam que o livro está adequado aos objetivos da escola de preparação dos estudantes para concursos vestibulares. Alguns professores chegaram a justificar o porquê de considerar essa proposta, para oferecer aos estudantes que farão os concursos vestibulares a oportunidade de ter acesso aos conteúdos relacionados no programa do vestibular seriado/UFSM. Mas, admitindo que não sejam todos os estudantes que farão vestibular, qual será o sentido do Ensino Médio para eles? Esses estudantes também terão suas expectativas contempladas? Quando um professor assume que serão atendidos os objetivos de apenas parte dos estudantes, não está, na verdade, desconsiderando a realidade da escola e dos alunos?

Parece não haver, portanto, um consenso sobre as reais finalidades do 
Ensino Médio: enquanto a legislação educacional aponta para um caminho, muitos professores, pressionados por alunos e familiares, caminham na contramão do que se espera de uma boa formação básica, na medida em que atribuem ao Ensino Médio apenas a finalidade de preparação para o ingresso no ensino superior, que, no nosso caso, se reduz à preparação para ingresso na UFSM.

\section{CONCLUSÕES}

Podemos afirmar, a partir dos resultados obtidos, que a utilização do Livro Didático pelo professor, tanto na organização de suas aulas, como em sala de aula com os alunos, tem os exercícios como ponto central e segue uma forma já naturalizada de ensinar Física. Na definição dos conteúdos de ensino e da sequência didática de assuntos, o LD não assume nenhum papel relevante, uma vez que quase todos os professores adotam o Programa PEIES/UFSM (Exame Vestibular Seriado) como base. Seguindo esse Programa, os professores preparam suas aulas utilizando o livro como uma fonte para obtenção de listagens já organizadas de exercícios, para resolução pelos alunos, e para enriquecer sua "intervenção didática", que, em geral, já está previamente determinada por outros fatores.

Para a organização das aulas, outros materiais também costumam ser utilizados, prevalecendo os Sistemas Apostilados de Ensino, as revistas, semanais ou mensais, os jornais diários e os materiais obtidos pela internet. Assim, ainda que esses materiais sejam utilizados nas aulas de Física com menor frequência e com uma finalidade complementar, pode-se dizer que os livros não têm sido o único material utilizado pelos professores de Física na organização de suas aulas, o que reafirma os resultados de Megid Neto e Fracalanza (2003), Santos (2007) e Baganha (2010).

Em geral, os professores retiram dessas outras fontes materiais para subsidiar a realização de atividades didáticas diferentes daquelas que preparam a partir das indicações existentes no livro didático adotado. Alguns livros que têm uma abordagem e uma programação diferentes daquela usualmente seguida na região considerada também têm sido utilizados por alguns professores como materiais adicionais para a realização de atividades complementares.

De modo geral, em sala de aula, o papel do LD adotado restringe-se ao de fonte de listagens de exercícios para os alunos resolverem e, em alguns casos, ao de fonte para leitura sobre o assunto tratado (texto principal de um capítulo), como também apontam os estudos de Timbo (2009), Miranda (2009) e Guimarães (2011). É surpreendente perceber que esse resultado também é muito semelhante ao encontrado no estudo de Décio Pacheco, realizado ainda no final da década de 1970, com professores de Física. Naquela época, os livros eram constituídos basicamente de um texto principal, seguido de exercícios e de leituras complementares. Assim, Pacheco, no desenvolvimento de seu trabalho de mestrado, constatou que,

(...) com exceção da parte referente às suas "leituras complementares", os professores têm solicitado que seus alunos consultem todas as outras, dando maior ênfase, no entanto, à parte que contém os "exercícios a serem resolvidos” (PACHECO, 1979, p.155, grifos nossos). 
Podemos dizer que os professores de Física investigados não fícam presos aos Livros Didáticos, contrariando o que se costuma assumir, no campo educacional, como pressuposto em relação às aulas de Física. Por outro lado, esses professores parecem ficar vinculados a uma "forma" de ensinar Física que foi sendo constituída em parte pela tradição já adotada de como ensinar Física e em parte pela sua própria experiência docente (saber experiencial), o que acaba se consolidando como uma "norma" para o desenvolvimento de suas aulas. Essa "forma", baseada na exposição do professor, seguida da resolução de um número grande de exercícios pelos alunos, é tão forte que mesmo a presença de livros, reafirmada de modo mais intenso a partir do PNLD, alguns com características interessantes e inovadoras, não tem alterado essa forma de desenvolver as aulas.

As aulas de Física parecem continuar, portanto, com a mesma dinâmica daquelas que aconteciam anteriormente à distribuição de Livros Didáticos a todos os alunos pelo Governo Federal.

O que mudou, então? Os depoimentos dos professores sugerem que os alunos, agora, não precisam gastar o período da aula para copiar, em seus cadernos, longos textos arduamente reproduzidos pelo professor no quadro. Também não precisam estudar com base em textos organizados pelo professor (usualmente, um verdadeiro "Frankenstein"), a partir da cópia de extratos de vários livros, ou a partir de sistemas apostilados, alguns de qualidade duvidosa, de cursinhos de pré-vestibular ou elaboradas por outros professores, e vendidos na forma de cópias reprográficas (xérox). Os alunos dispõem agora de um texto que, se não é lido e discutido em sala de aula, ao menos está à disposição em sua casa, para estudos posteriores.

Outra característica parece permanecer: a resolução, por parte dos alunos, de uma grande quantidade de exercícios, o que sugere uma concepção ainda bastante presente de aprendizagem, baseada no "treinamento" e na "memorização".

Assim, conforme as informações coletadas, é com essa função "reduzida" - a de oferecer uma listagem já organizada de exercícios - que o LD tem sido recorrentemente utilizado, ou subutilizado.

É bastante razoável afirmar, portanto, que um condicionante principal para a utilização dos Livros Didáticos adotados é a manutenção de uma forma tradicional de ensinar Física, à qual se adicionam alguns elementos mais "inovadores" que chamam a atenção dos alunos, mas que não passam de uma maneira de reproduzir aquela forma tradicional, uma vez que possuem função complementar e são utilizados com pouca freqüência. Afinal, como afirmam alguns professores investigados: "tem que dar o conteúdo e andar”!

Ressalta-se, assim, a influência do exame vestibular seriado/UFSM nas aulas de Física das escolas da região considerada, pois um dos aspectos que parece causar a manutenção desse modo de ensinar Física (tradicional) e de uso do livro didático é a obstinação em "vencer" todos os assuntos elencados nesse exame. A esse respeito, fazemos nossas as palavras dos autores Lima e Silva, estendendo ao Ensino de Física o que eles afirmam sobre o Ensino de Química:

Acreditamos que uma mudança significativa na prática do ensino de Química só deverá ocorrer quando a ênfase que damos à quantidade do que se ensina der lugar à importância conferida à qualidade do que se aprende. O tempo [gasto] com o que se ensina é diferente 
do tempo gasto no que se aprende. Antes que isso ocorra, a pressa em vencer os conteúdos será inimiga dos processos que dão maior ênfase ao desenvolvimento e à formação de conceitos. (LIMA, SILVA, 2010, p.128)

Por isso, enquanto o Ensino de Física, do mesmo modo que o ensino das outras disciplinas escolares, girar em torno de programações definidas por outras instâncias, que não o coletivo de cada escola, e a preocupação dessas escolas for a de "vencer os conteúdos" estabelecidos nessas programações, não será o LD nem outro material didático que poderá auxiliar na melhoria da qualificação da Educação Escolar.

Percebemos, ainda, que muitos professores não se sentem preparados para utilizar um livro que foge à abordagem à qual eles já estão acostumados. Muitos desses professores, ao longo dos anos de experiência docente, consolidaram uma forma de ensinar que, de seu ponto de vista, é eficiente. Como as mudanças são difíceis, em especial nesse caso, em que está em jogo uma transformação ampla, às vezes até em suas concepções de ensino e de aprendizagem, então tem prevalecido a conservação/manutenção de suas práticas.

De qualquer modo, mesmo quando o Livro Didático apresenta alternativas diversas para realizar um Ensino de Física diferente da forma típica (leitura e resolução de exercícios), apresentando experimentos didático-científicos, textos de História da Física, propondo realização de atividades práticas, incentivando o pensamento crítico em relação às aplicações dos conhecimentos físicos etc., ainda assim tem prevalecido um uso limitado dos livros, focado basicamente no texto principal e nos exercícios propostos.

Com isso não estamos dizendo que o professor deveria adotar o livro e trabalhar todas suas partes de forma integral, utilizando-o como um "manual". Certamente isso não tornaria o professor mais autônomo na realização de seu trabalho. O que estamos apontando é o fato de que a utilização do livro tem sido feita de modo a conservar uma forma habitual de desenvolvimento das aulas de Física, caracterizada pela exposição do professor e pela resolução de exercícios pelos alunos.

Assim, se havia a intenção de, a longo prazo, melhorar, de alguma forma, o ensino na educação básica, devido à distribuição de livros didáticos, com qualidade superior aos seus congêneres, podemos afirmar que, no contexto avaliado, isso não tem acontecido. Isso mostra que a simples ação de distribuição de livros não pode, sozinha, melhorar o ensino, a menos que se invista - dentre outros aspectos - na formação continuada dos professores em serviço e na melhoria das condições de trabalhos dos professores.

\section{REFERÊNCIAS}

BAGANHA, Denise E. O papel e o uso do Livro Didático de ciências nos anos finais do ensino fundamental. 2010. Dissertação (Mestrado em Educação) - Setor de Educação. Programa de Pós-Graduação em Educação. Universidade Federal do Paraná. Curitiba. 2010.

CASSAB, M.; MARTINS, I. Significações de professores de ciências a respeito do livro didático. Ensaio: Pesquisa em Educação em Ciências, Belo Horizonte, 2008, v. 10, n. 1, p. 1-28.

ESPÍNDOLA, Danielle P. A. O uso do Livro Didático em sala de aula, por professores de História. 2003. 
Dissertação (Mestrado em Educação) - Faculdade de Educação. Universidade Federal de Minas Gerais. Belo Horizonte. 2003.

FREITAG, B.; MOTTA, V. R.; COSTA, W. F. O estado da arte do livro didático no Brasil. Brasília: Reduc. 1987. GAUTHIER, C. et al. Por uma teoria da pedagogia: pesquisas contemporâneas sobre o saber docente. Trad. Francisco Pereira de Lima. 2. ed. Ijuí: Editora da UNIJUÍ. (Coleção "Fronteiras da Educação"). 2006. ISBN 85-7429-003-3.

GIBBS, Graham. Análise de dados qualitativos. Trad. Roberto Cataldo Costa. Porto Alegre: Artmed. 2009. ISBN 978-85-363-2055-7

GUIMARÃES, F. M. Como os professores de $6^{\circ}$ ao $9^{\circ}$ anos usam o livro didático de ciências. 2011. Dissertação (Mestrado em Educação) - Faculdade de Educação, Universidade Estadual de Campinas, Campinas. 2011.

LIMA, Maria E. C. de C.; SILVA, P. S. Critérios que professores de química apontam como orientadores da escolha do livro didático. Revista Ensaio, Belo Horizonte, v. 12, n. 2, p. 121-136, 2010.

MEGID NETO, Jorge; FRACALANZA, Hilário. O Livro Didático de Ciências: Problemas e Soluções. Ciência \& Educação, Bauru, v. 9, n. 2, p. 147-157,2003.

MIRANDA, Luciana C. Alguns Aspectos que influenciam a escolha e o uso do livro didático pelos Professores das Ciências Naturais na Educação Básica. 2009. Dissertação (Mestrado em Educação) - Faculdade de Educação, Universidade Federal de Minas Gerais. 2009.

MOLINA, Olga. Quem engana quem: Professor x Livro Didático. 2. ed: Campinas: Papirus, 1988.

MUNAKATA, Kazumi. Livro Didático e Formação de Professores são incompatíveis? In: CONGRESSO BRASILEIRO DE QUALIDADE NA EDUCAÇÃO: FORMAÇÃO DE PROFESSORES, 2002, Brasília. Anais...Simpósio 6. Brasília: MEC/SEF, p.89-94. Disponível em: http://portal.mec.gov.br/seb/arquivos/pdf/vol1b.pdf. Acesso em: set/2011

PACHECO, D. Análise dos exercícios propostos nos livros ddáticos de Física adotados nas escolas de segundo grau de Campinas. 1979. Dissertação (Mestrado em Educação) - Faculdade de Educação, Universidade Estadual de Campinas, Campinas. 1979.

PRETTO, Nelson de Luca. A ciência nos livros didáticos. Bahia: Editora da UNICAMP. 1985.

ROJO, Roxane. 'Livros em sala de aula: modos de usar'. In: BRASIL, MEC. Materiais Didáticos: escolba e uso. 2005. p. 35-42. (Boletim 14).

SANTOS, Célia R. S. A mediação do livro didático de Física em um processo de ensino-aprendizagem. 2001. Dissertação (Mestrado em Educação) - Universidade Metodista de Piracicaba. 2001.

SANTOS, Cibele M. C. dos. O livro didático: as escolhas do professor. 2007. Dissertação (Mestrado em Educação) - Setor de Educação. Programa de Pós-Graduação em Educação. Universidade Federal do Paraná. Curitiba. 2007.

SANTOS, Cícero G. dos. Livro didático de português: da proposta teórico-metodológica às adaptações no ensino da escrita. 2009. Dissertação (Mestrado em Educação) - Universidade Federal de Campina Grande. 2009.

TIMBO, Isaide B. O livro didático de história: um caleidoscópio de escolhas e usos no cotidiano escolar (Ceará, 20072009). 2009. Dissertação (Mestrado em Educação) - Universidade Federal do Rio Grande do Norte. 2009.

ZAMBON, L. B. Seleção e utilização de livros didáticos de física em escolas de educação básica. 2012. Dissertação (Mestrado em Educação) - Universidade Federal de Santa Maria. 2012

\section{NOTAS}

${ }^{1}$ Os periódicos consultados foram: (1) Alexandria: Revista de Educaşão em Ciência e Tecnologia, (2) Caderno Brasileiro de Ensino de Física, (3) Ciência \& Educaşão, (4) Ciência \& Ensino, (5) Ensaio - Pesquisa em Educação em Ciências, (6) Experiências em Ensino de Ciências, (7) Investigaçoes em Ensino de Ciências, (8) Revista Brasileira de Ensino de Física, (9) Revista Brasileira de Pesquisa em Educação em Ciências.

${ }^{2}$ Apostilas didáticas elaboradas por empresas privadas do campo educacional. 
Submetido em 12/04/16

Aprovado em 22/05/17

Contato:

Luciana Bagolin Zambon

Avenida Roraima, 1000. Campus Universitário UFSM.

CEP: 97105-900 - Camobi, Santa Maria - RS. 


\section{APÊNDICE}

Itens dos Roteiros de Questionário e de Entrevista utilizados para responder às questões de pesquisa propostas*

\begin{tabular}{|c|c|c|c|}
\hline $\mathbf{N}$ & $\begin{array}{l}\text { Fonte de } \\
\text { Informação }\end{array}$ & $\begin{array}{l}\text { Instrumento } \\
\text { de Pesquisa }\end{array}$ & $\begin{array}{c}\text { Questões do Roteiro } \\
\text { (Extrato dos Roteiros completos utilizados) }\end{array}$ \\
\hline 1 & $\begin{array}{c}\text { Sujeitos - } \\
\text { Professores } \\
\text { de Física }\end{array}$ & Questionário & $\begin{array}{l}\text { 1. Que materiais você utiliza para preparar suas aulas? } \\
\text { 2. Você utilizava livros didáticos, antes da distribuição } \\
\text { de livros de Física pelo MEC no âmbito do Programa } \\
\text { Nacional do Livro para o Ensino Médio (PNLEM 2007)? } \\
\text { 4. Você utiliza o livro didático recebido? }\end{array}$ \\
\hline 2 & $\begin{array}{c}\text { Sujeitos - } \\
\text { Professores } \\
\text { de Física }\end{array}$ & Entrevista & $\begin{array}{l}\text { 1. Como você utiliza livros didáticos para a preparação } \\
\text { das aulas? } \\
\text { 2. Como é o trabalho com o livro didático em sala de } \\
\text { aula? (que mecanismos utiliza para desenvolver as } \\
\text { aulas com o livro: leitura individual, em grupo, no } \\
\text { grande grupo; como trabalha com exercícios? que } \\
\text { seções do livro são trabalhadas?) } \\
\text { 3. Que importância você atribui ao Livro Didático na } \\
\text { preparação e no desenvolvimento de suas aulas? } \\
\text { 4. Como você organiza a sequência dos conteúdos da } \\
\text { estrutura conceitual da Física? (em cada série) } \\
\text { 5. Qual o peso (a participação) do livro na decisão sobre } \\
\text { a sequência dos conteúdos? } \\
\text { 22. De que forma o livro didático selecionado atende às } \\
\text { orientações expressas nos documentos de sua escola } \\
\text { para o Ensino Médio? E para a disciplina de Física? }\end{array}$ \\
\hline
\end{tabular}

*A íntegra dos Roteiros de Questionário e de Entrevista encontra-se em Zambon (2012). 